\title{
Design and Analysis of Zeta Converter for Automotive Mechatronics Applications
}

\author{
Shunmathi $\mathbf{M}^{*}$ \\ Thiagarajar college of Engineering, Madurai, India. \\ *Corresponding Author: Shunmathi M, Thiagarajar college of Engineering, Madurai, India.

\begin{abstract}
This study deals with power factor correction converter based bridgeless zeta converter for brushless DC (BLDC) motor drive for medium and low power applications. In brushless motors are used to pick and place robot, object to assign particular positioning and actuation applications. The voltage source inverter (VSI) used for obtaining the electronic commutation of BLDC motor for reducing conduction losses and switching losses. The zeta converter operates in discontinuous mode of operation. The proposed zeta converter to provide regulated DC voltage for BLDC motor and to reduce source current total harmonic distortion (THD) at AC mains. The speed of BLDC motor has been controlled by varying the DC-link voltage of VSI and compare between both diode bridge Rectifier (DBR) and bridgeless converter of the BLDC motor drive.
\end{abstract}

Keywords: Voltage source inverter, Bridgeless converter, Total harmonic distortion, Diode bridge rectifier.

\section{INTRODUCTION}

Brushless dc motor is a permanent magnet synchronous electric motor to driven to operate by direct current and its electrically controlled operating commutation system. In electronic commutation is the process of producing rotational torque in the motor by changing phase current through it instead of mechanical commutation. Mostly used for Hall sensor used to sense the position of the rotor and are position around the stator. The rotor position feedback from the sensor helps to determine the armature current. Stator of a BLDC made up stacked steel laminations to carry the winding. For robotics automotive and small actuating applications $48 \mathrm{~V}, 400 \mathrm{~W}$. In order to achieve maximum torque in the motor, the flux density of the material should be high. A proper magnetic field for the motor is needed to produce required magnetic field density. The main design difference between brushed and brushless motors is the replacement of mechanical commutator with an electric switch circuit. BLDC Motor is a type of synchronous motor in the sense that the magnetic field generated by the stator and the rotor revolve at the same frequency, no brushes in a BLDC Motor, the commutation is controlled electronically. In order to rotate the motor, the windings of the stator must be energized in a sequence and the position of the rotor (i.e. the North and South poles of the rotor) must be known to precisely energize a particular set of stator windings.

A Position Sensor, which is usually a Hall Sensor (that works on the principle of Hall Effect), is generally used to detect the position of the rotor and transform it into an electrical signal. Most BLDC Motors use three Hall Sensors that are embedded into the stator to sense the rotor's position. The output of the Hall Sensor will be either HIGH or LOW depending on whether the North or South Pole of the rotor passes near it. By combining the results from the three sensors, the exact sequence of energizing can be determined. In recent years BLDC motors are widely used in wide range of speed control, Industrial-drives, Medical application. Brushless dc motors are recommended for many low and medium power applications because of their high efficiency. In some features of BLDC motor exhibit better heat dissipation, improved efficiency and greater power density. High torque and a very wide speed range. Compact size, reduced weight and high speed range. Many single phase power factor correction converters are reported in the literature for feeding the BLDC motor drive. In bridge and bridgeless converter topology mainly used for automotive applications. Mainly focus on power factor 
correction converter and reduce THD and improve power factor. This allows the operation of VSI in fundamental frequency switching for achieving an electronic commutation of BLDC motor drive.

\section{FunCtional Block Diagram:}

In single phase ac supply and voltage source inverter and BLDC motor connected in power factor correction converter. In gating pulses applied in the voltage source inverter. To compare the reference voltage and actual voltage of the PFC converter.

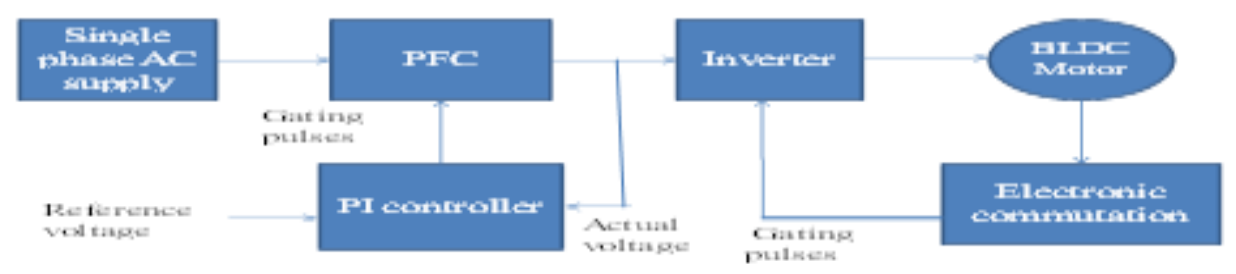

Figure1. Block Diagram

\section{Proposed Zeta Converter:}

\subsection{Basic Operation of Zeta Converter}

Zeta converter consists of one switch and two inductor, one diode and two capacitor and resistive load connected in the circuit. Zeta converter operating under continuous mode and discontinuous mode of operation.

\section{Mode of operations:}

\section{Mode 1:}

In switch is on condition the diode to conduct reverse biased and inductor current flow from source voltage those current flows through the inductor start to get increase linear and stored some energy. The inductor voltage appear across equal to the input voltage. In same time capacitor $\mathrm{C} 1$ starts charged and gets output voltage. When MOSFET is in ON condition, energy from the supply will be stored in the two inductors (L1, L2).
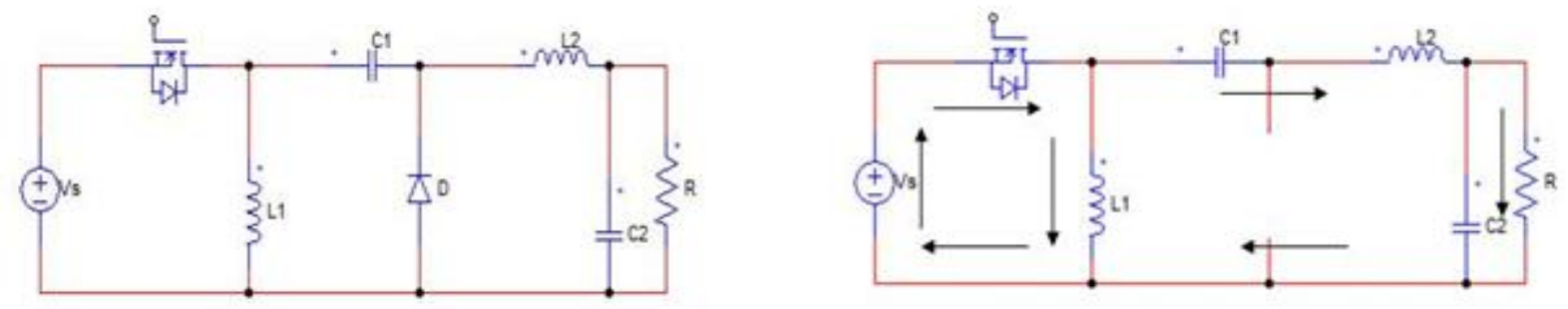

Figure2. Circuit Diagram of Zeta Converter and Mode1

Mode 2:

In switch is off condition the diode to conduct forward biased and L2 inductor and across the inductor output voltage. $\mathrm{C} 1$ is discharged and $\mathrm{C} 2$ is charged to voltage in output.

Whatever energy stored in the inductor $(\mathrm{L})$ will be carry forward to the load resistor. So this kind of mode of operation is discharging conditions.

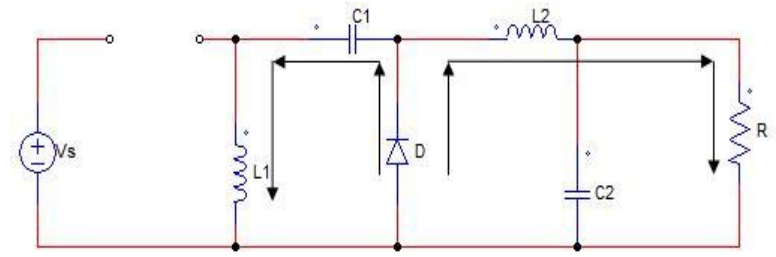

Figure3. Circuit Diagram of Zeta Converter and Mode 2 
Mode of operations:

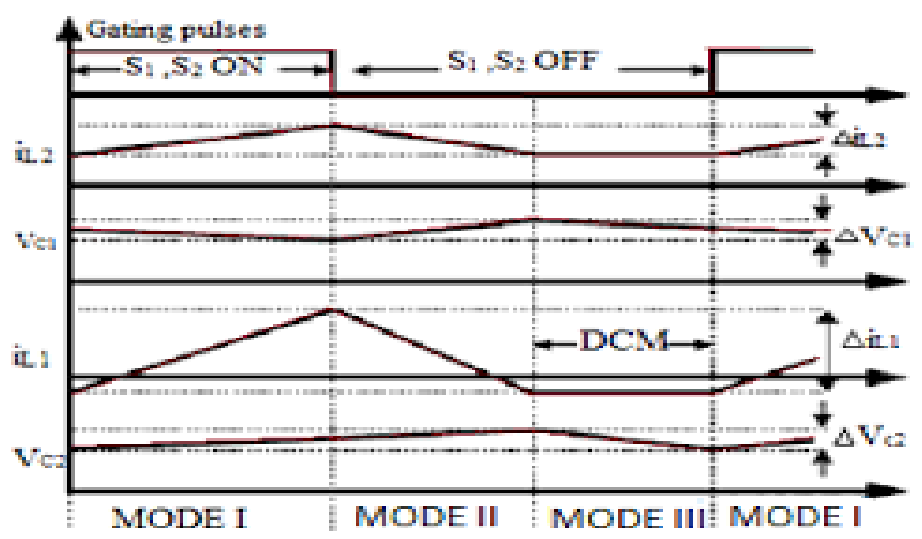

Figure4. Mode of Operation of Zeta Converter

\section{Design And Analysis Of Zeta Converter:}

The PFC zeta converter is designed to operate under discontinuous mode of operation the current flowing in input inductor (L) becomes discontinuous in a conduction period. In converter design of 200 $\mathrm{W}$ is designed to feed BLDC motor. In voltage regulate $48 \mathrm{~V}$ at output side of the converter. To calculate the value of output voltage and output inductor and input side of inductor filter and capacitance value. To compare and Result analysis of bridge rectifier and bridgeless converter fed BLDC motor drive.

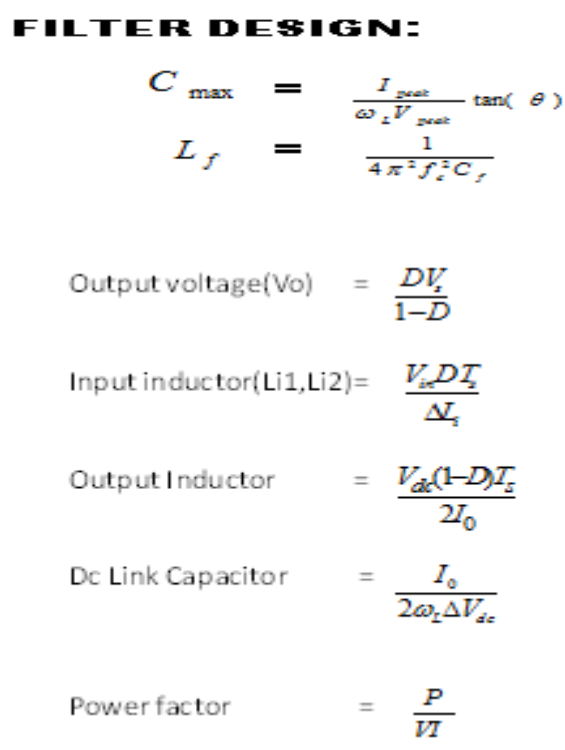

\subsection{Matlab Simulink Diagram for Zeta Converter Fed BLDC Motor:}

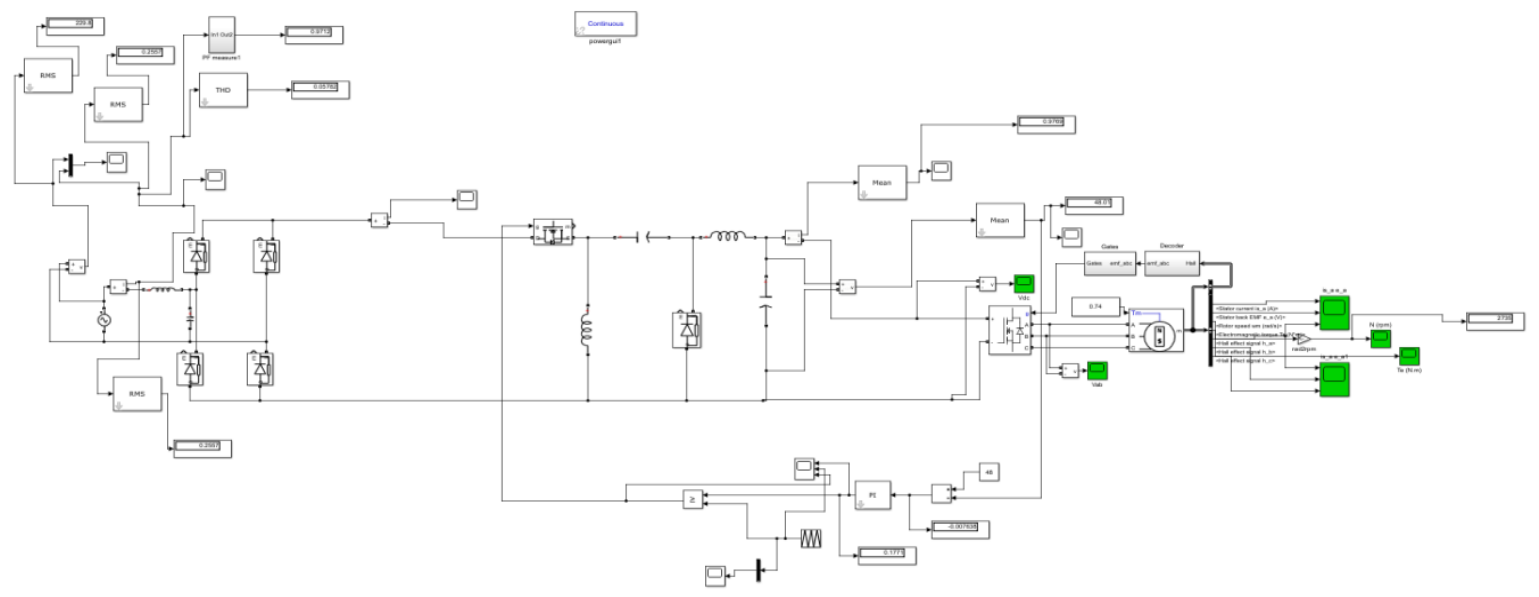

Figure5. Matlab Simulink for Zeta Converter Fed BLDC Motor 


\subsection{Result Analysis of Zeta Converter:}

To compare the results in diode bridge rectifier fed BLDC motor and bridgeless zeta converter fed BLDC motor drive.

\subsubsection{Diode Bridge Rectifier Fed BLDC Motor Drive:}

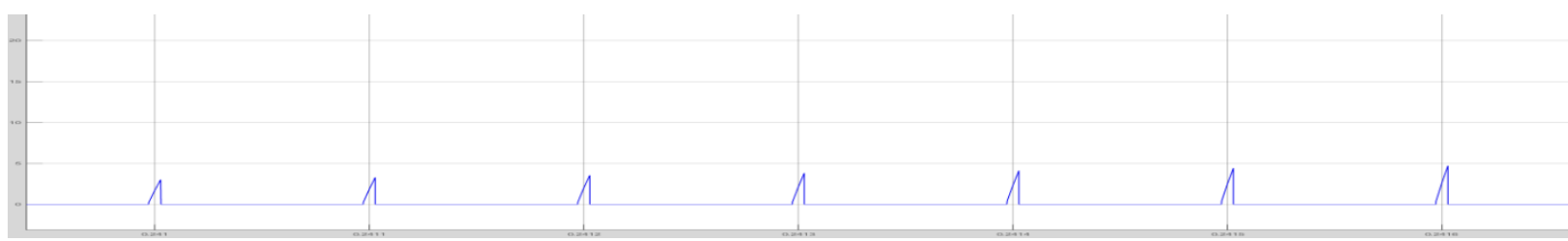

Figure6. Diode Bridge Rectifier Current Waveform
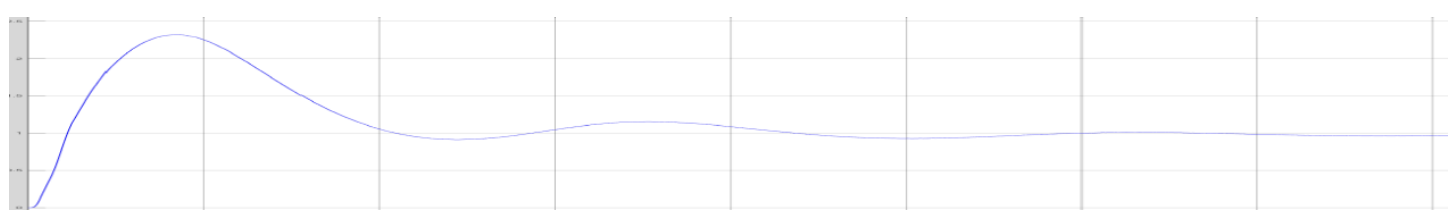

Figure7. Output current waveform

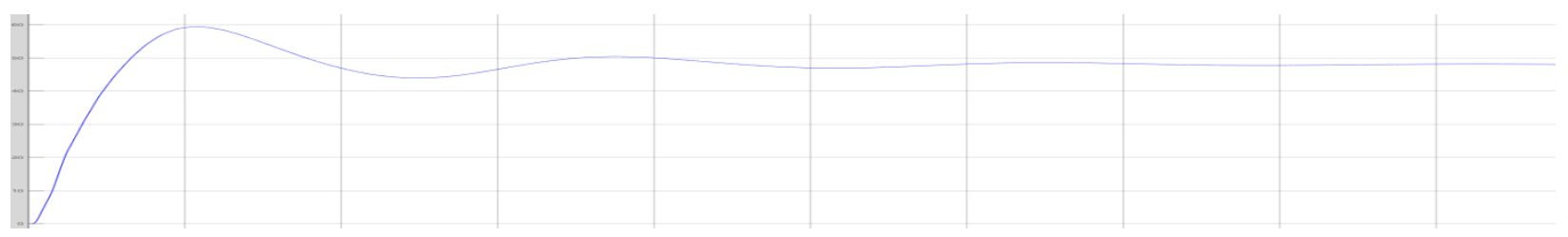

Figure8. Output Voltage Waveform
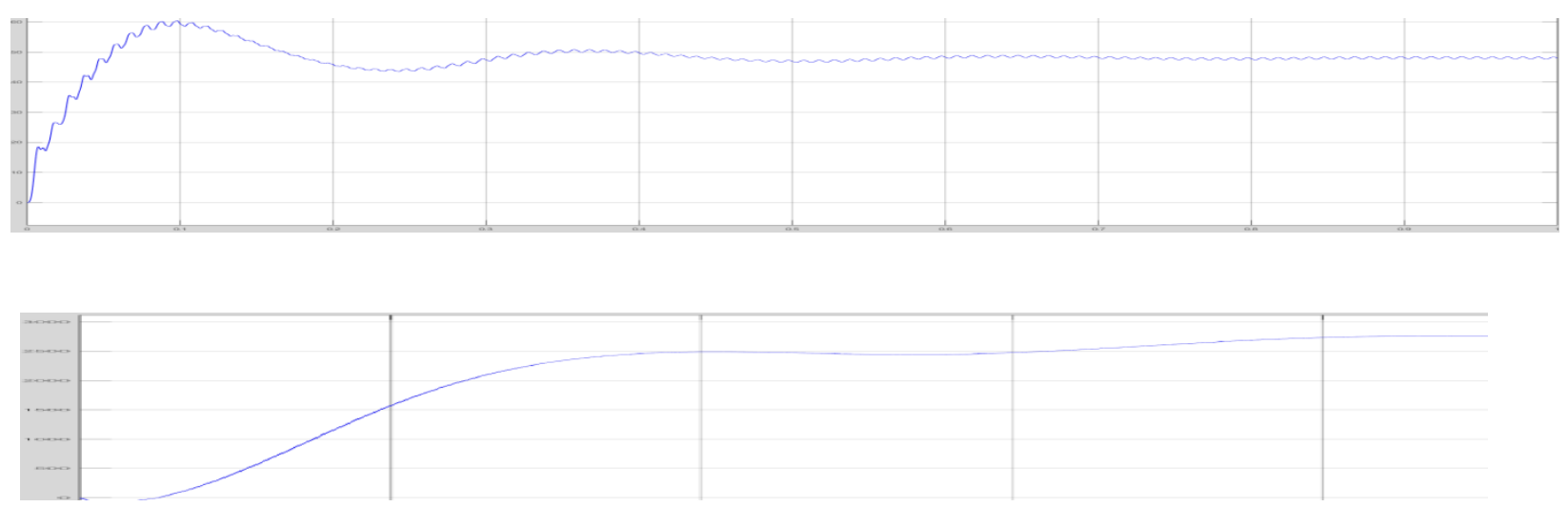

Figure9. Motor Speed

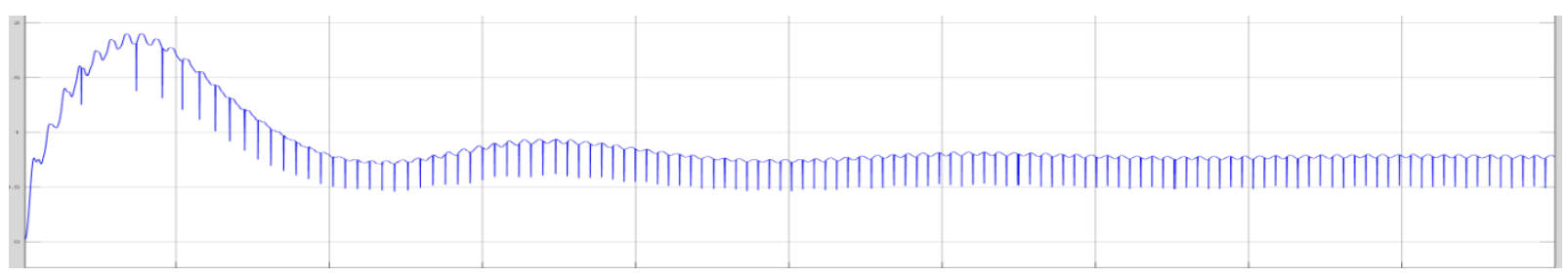

Figure10. Torque

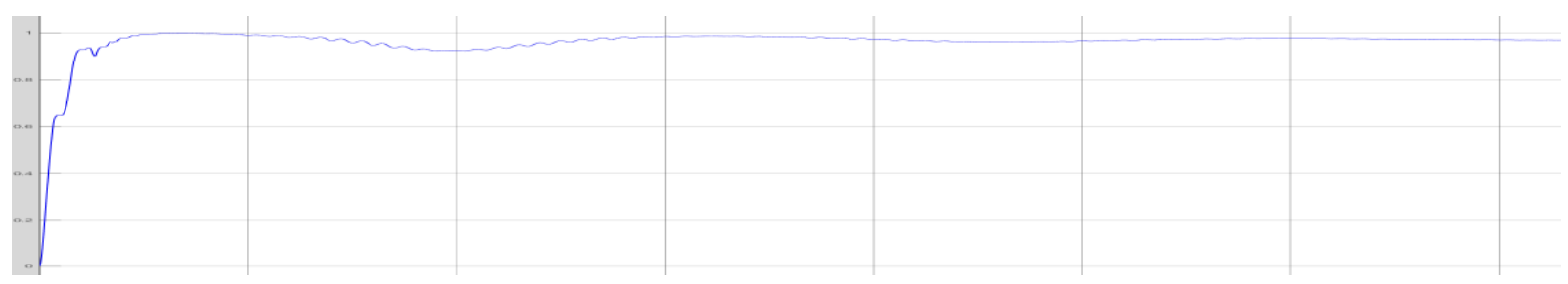

Figure11. Power factor 

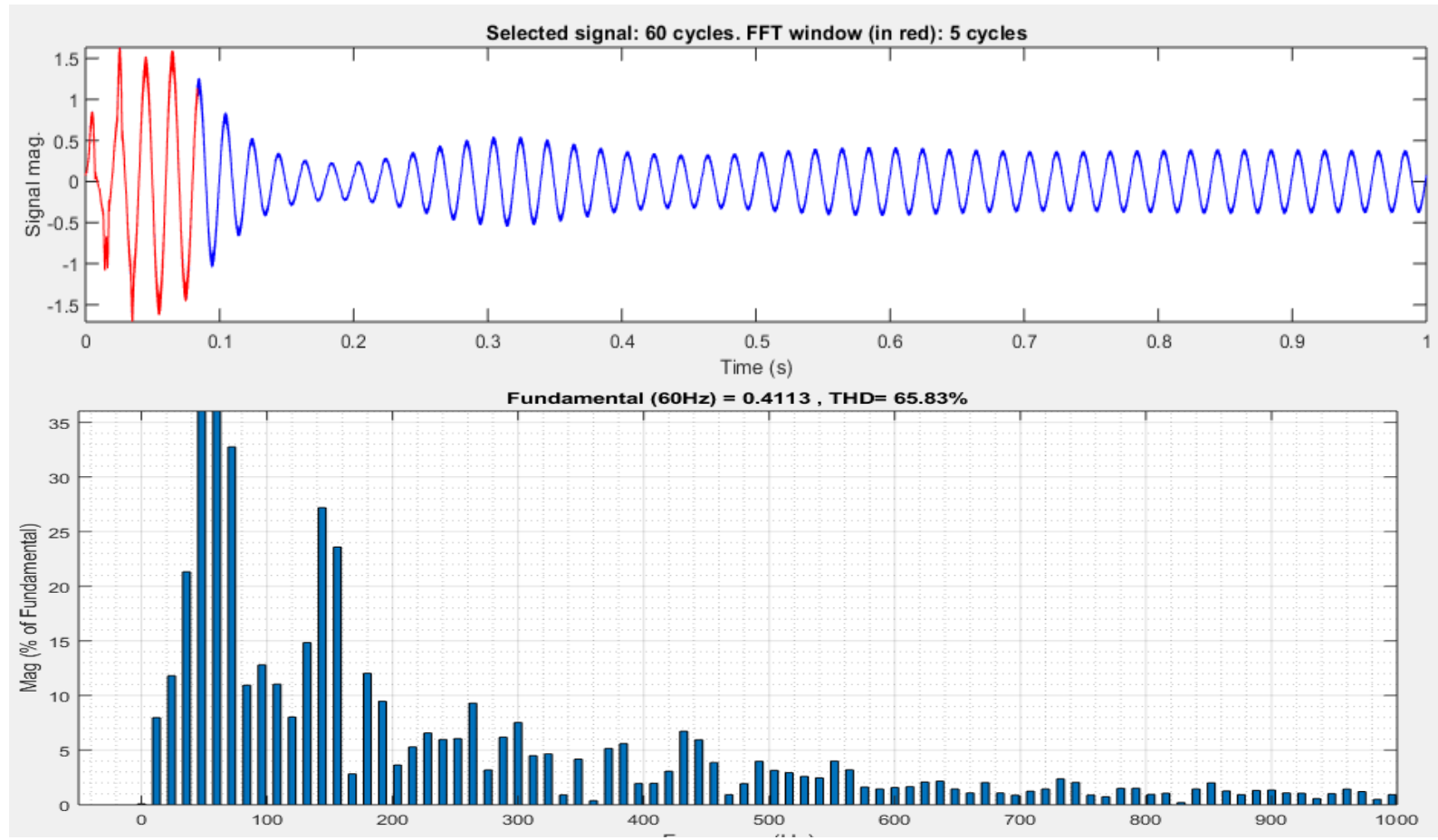

Figure12. THD Analysis

4.2.2. Bridgeless Zeta Converter Fed BLDC Motor Drive:

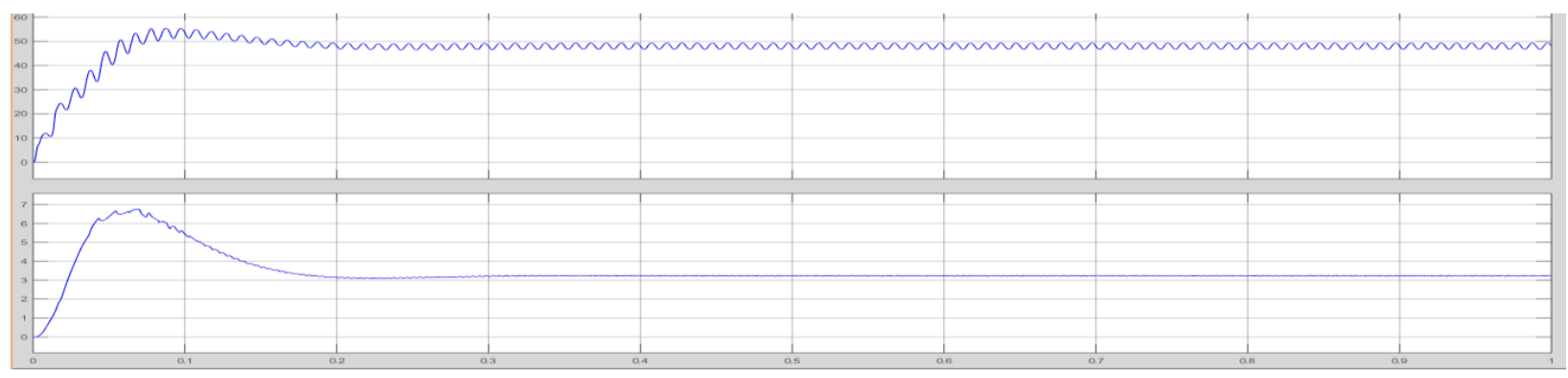

Figure13. Output Voltage, Current Waveform

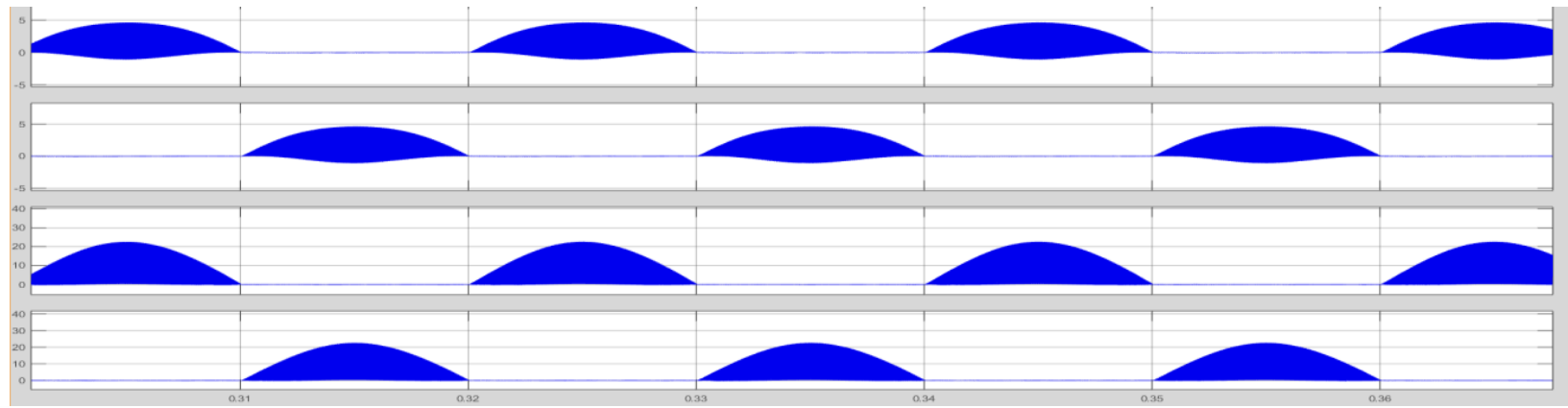

Figure14. Diode Current Waveform

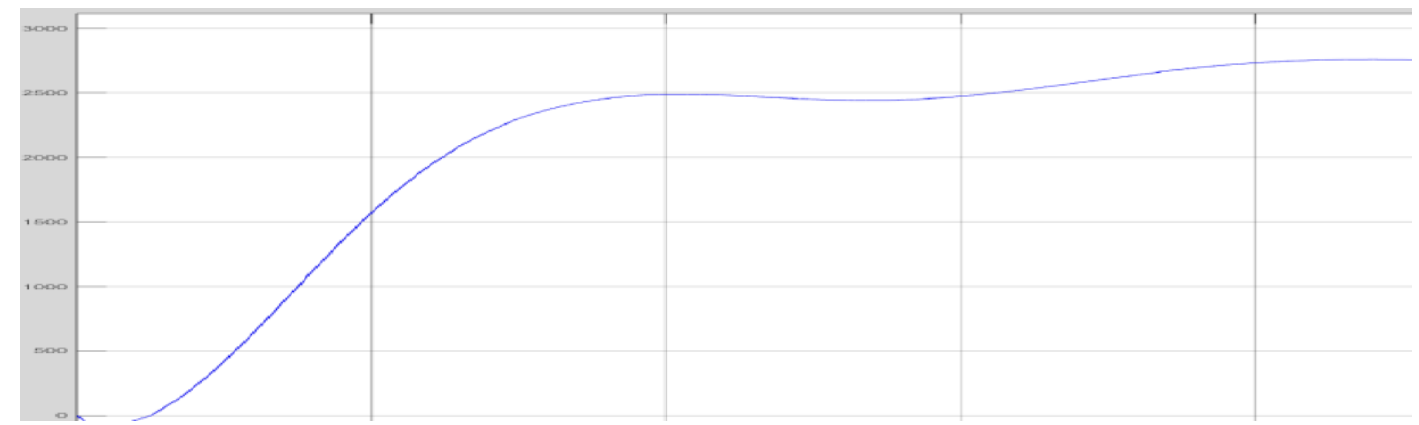

Figure15. Motor Speed 


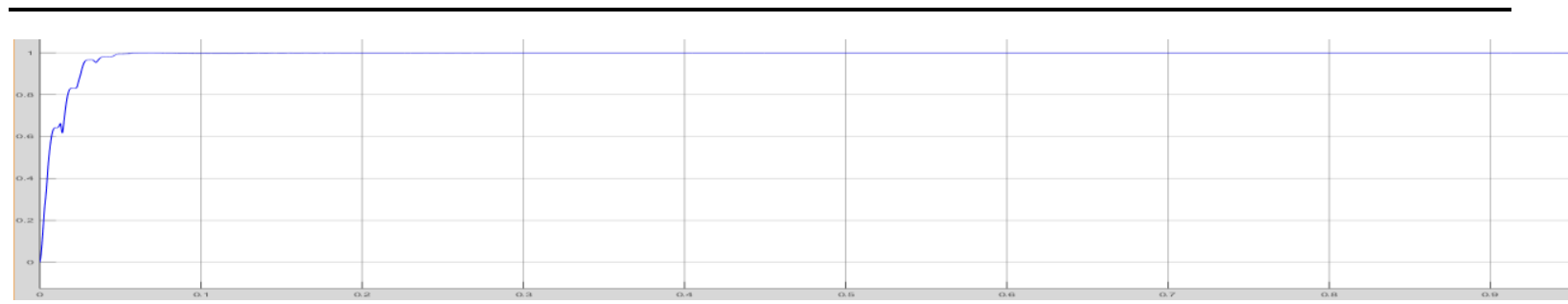

Figure16. Power Factor

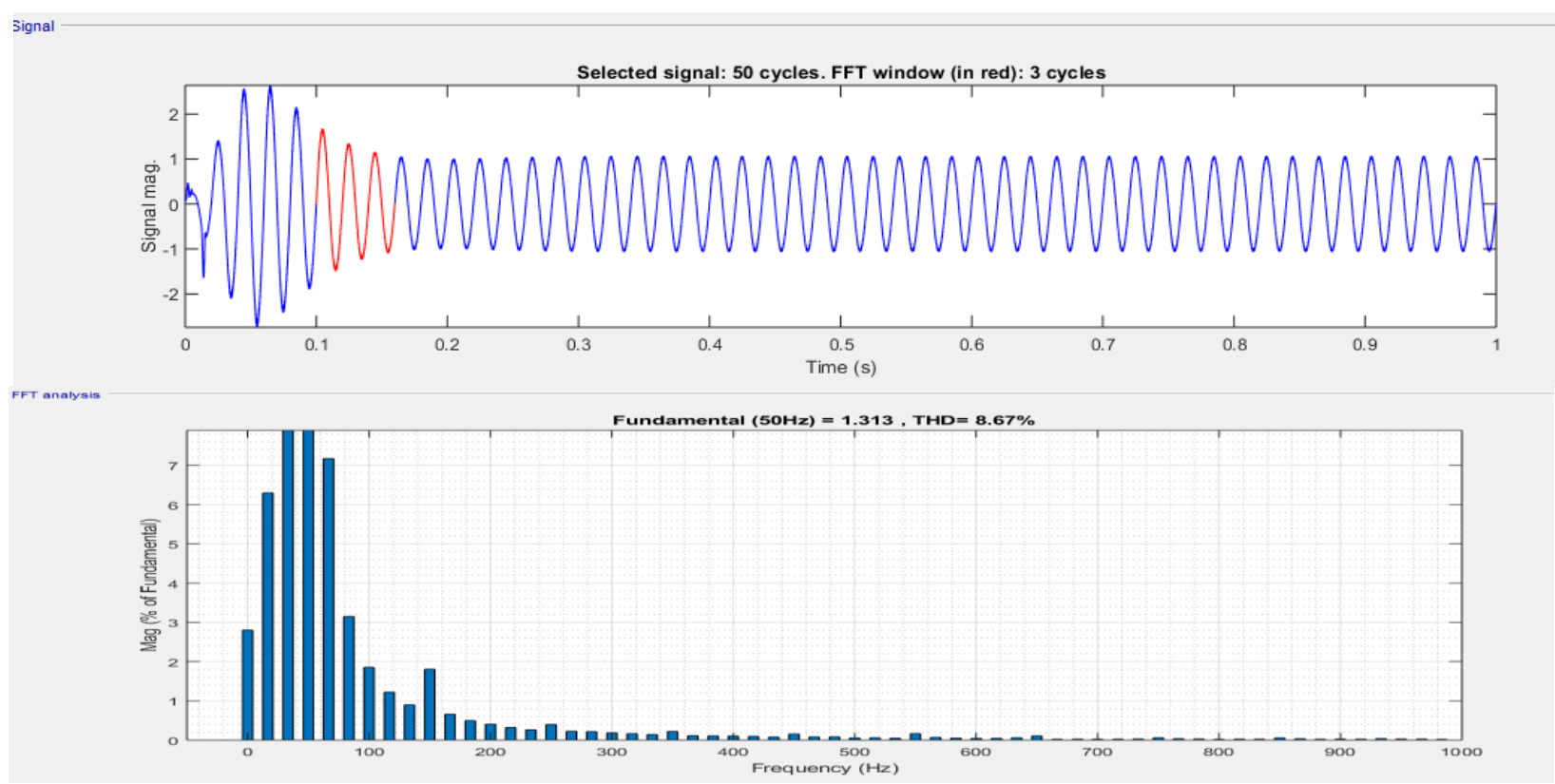

Figure17. Thd Analysis

4.2.3. Variation of Torque: (For Bridge Rectifier)

Output Regulating Voltage: 48v

\begin{tabular}{|c|c|c|c|c|c|}
\hline $\begin{array}{c}\text { TORQUE } \\
(\mathbf{N}-M)\end{array}$ & $\begin{array}{c}\text { SPEED } \\
\text { (RPM) }\end{array}$ & $\begin{array}{c}\text { SOURCE } \\
\text { CURRENT } \\
\text { THD } \\
(\boldsymbol{\%})\end{array}$ & $\begin{array}{c}\text { INPUT } \\
\text { POWER } \\
\text { FACTOR }\end{array}$ & $\begin{array}{c}\text { OUTPUT } \\
\text { CURRENT } \\
(\mathbf{A})\end{array}$ & $\begin{array}{c}\text { SOURSE } \\
\text { CURRENT } \\
(\mathbf{A})\end{array}$ \\
\hline 0.74 & 2735 & 75.2 & 0.9712 & 0.9769 & 0.255 \\
\hline 0.72 & 2782 & 74.8 & 0.9699 & 0.9524 & 0.250 \\
\hline 0.70 & 2829 & 74.2 & 0.968 & 0.9286 & 0.244 \\
\hline 0.64 & 2969 & 73.2 & 0.964 & 0.859 & 0.229 \\
\hline 0.63 & 2992 & 70.6 & 0.963 & 0.848 & 0.227 \\
\hline 0.5 & 3291 & 68.5 & 0.953 & 0.649 & 0.194 \\
\hline 0.45 & 3516 & 67.3 & 0.934 & 0.566 & 0.1877 \\
\hline 0.4 & 3605 & 67.2 & 0.943 & 0.435 & 0.1819 \\
\hline 0.3 & 3755 & 65.8 & 0.933 & 0.325 & 0.135 \\
\hline 0.1 & 4235 & 65.2 & 0.932 & 0.223 & 0.088 \\
\hline
\end{tabular}

4.2.4. Variation of Torque: (For Bridgeless converter)

Output Regulating Voltage: $48 \mathrm{v}$

\begin{tabular}{|c|c|c|c|c|c|}
\hline $\begin{array}{c}\text { TORQUE } \\
(\mathbf{N}-M)\end{array}$ & $\begin{array}{c}\text { SPEED } \\
(\text { RPM) }\end{array}$ & $\begin{array}{c}\text { SOURCE } \\
\text { CURRENT } \\
\text { THD } \\
(\%)\end{array}$ & $\begin{array}{c}\text { INPUT } \\
\text { POWER } \\
\text { FACTOR }\end{array}$ & $\begin{array}{c}\text { OUTPUT } \\
\text { CURRENT } \\
(\mathbf{A})\end{array}$ & $\begin{array}{c}\text { SOURSE } \\
\text { CURRENT } \\
\text { (A) }\end{array}$ \\
\hline 0.74 & 4596 & 9.78 & 0.9998 & 3.19 & 0.735 \\
\hline 0.72 & 4617 & 9.81 & 0.9995 & 3.17 & 0.732 \\
\hline 0.70 & 4652 & 9.84 & 0.9993 & 3.16 & 0.729 \\
\hline 0.64 & 4679 & 9.94 & 0.9992 & 3.08 & 0.711 \\
\hline
\end{tabular}


Design and Analysis of Zeta Converter for Automotive Mechatronics Applications

\begin{tabular}{|c|c|c|c|c|c|}
\hline 0.63 & 4692 & 9.96 & 0.9985 & 3.04 & 0.708 \\
\hline 0.5 & 4827 & 8.67 & 0.9983 & 2.90 & 0.668 \\
\hline 0.45 & 4936 & 8.61 & 0.9978 & 2.83 & 0.653 \\
\hline 0.4 & 4884 & 8.64 & 0.9976 & 2.62 & 0.636 \\
\hline 0.3 & 5047 & 8.24 & 0.9974 & 2.58 & 0.606 \\
\hline 0.1 & 5275 & 8.23 & 0.9972 & 2.34 & 0.543 \\
\hline
\end{tabular}

\section{CONCLUSION:}

A zeta converter PFC converter based motor drive has been designed and developed for low power and speed control applications for ac mains. To compare the results in bridge rectifier and bridgeless converter and to reduce the THD and improve the input power factor and input side.To achieve minimum switching losses and conduction losses of the bridgeless converter. In low frequency switching operation of VSI with same voltage level to obtained. And finally calculate the input source current, speed, THD, output voltage, output current.

\section{REFERENCES}

[1] Xia, C.L.: 'Permanent magnet brushless DC motor drives and controls' (Wiley Press, Beijing, 2012)

[2] Kenjo, T., Nagamori, S.: 'Permanent magnet brushless DC motors' (Clarendon Press, Oxford, 1985)

[3] Handershot, J.R., Miller, T.J.E.: 'Design of brushless permanent magnet motors' (Clarendon Press, Oxford, 2010)

[4] Gieras, J.F., Wing, M.: 'Permanent magnet motor technology - design and application' (Marcel Dekker Inc., New York, 2002)

[5] Sokira, T.J., Jaffe, W.: 'Brushless DC motors: electronic commutation and control' (Tab Books, USA, 1989)

[6] Toliyat, H.A., Campbell, S.: 'DSP-based electromechanical motion control' (CRC Press, New York, 2004)

[7] Limits for Harmonic Current Emissions (Equipment input current $\leq 16$ A per phase), International Standard IEC 61000-3-2, 2000

[8] Singh, B., Singh, B.N., Chandra, A., Al-Haddad, K., Pandey, A., Kothari, D.P.: 'A review of single-phase improved power quality AC- DC converters', IEEE Trans. Ind. Electron., 2003, 50, (5), pp. 962-981

[9] Singh, B., Singh, S., Chandra, A., Al-Haddad, K.: 'Comprehensive study of single-phase AC-DC power factor corrected converters with high-frequency isolation', IEEE Trans. Ind. Inf., 2011, 7, (4), pp. 540-556

[10] Mohan, N., Undeland, T.M., Robbins, W.P.: 'Power electronics: converters, applications and design' (John Wiley and Sons Inc., USA, 1995)

[11] Singh, B., Singh, S.: 'Single-phase power factor controller topologies for permanent magnet brushless DC motor drives', IET Power Electron., 2010, 3, (2), pp. 147-175.

Citation: Shunmathi M (2020) "Design and Analysis of Zeta Converter for Automotive Mechatronics Applications", International Journal of Modern Studies in Mechanical Engineering, 6(1), pp.26-32. DOI: http://dx.doi. org/10.20431/2454-9711.0601004.

Copyright: (0) 2020 Authors, This is an open-access article distributed under the terms of the Creative Commons Attribution License, which permits unrestricted use, distribution, and reproduction in any medium, provided the original author and source are credited. 